\begin{tabular}{|l|l|l|l|l|l|}
\hline J. Tek. Ling & Vol.10 & No.3 & Hal. 337 - 346 & Jakarta, Sept 2009 & ISSN 1441-318X \\
\hline
\end{tabular}

\title{
TINGKAT KESUBURAN TANAH ULTISOL PADA LAHAN PERTAMBANGAN BATUBARA SANGATTA, KALIMANTAN TIMUR
}

\author{
Sudaryono \\ Peneliti Pusat Teknologi Lingkungan \\ Badan Pengkajian dan Penerapan Teknologi
}

\begin{abstract}
Most of the land in East Kalimantan is ultisol soil types with low soil fertility. In a large-scale land utisol used for oil palm, rubber and industrial plantations, but on a scale farmers because of economic constraints has led to the ground ultisol terkelolannya not well.

In general, land in coal mining utisol in Sangatta, East Kalimantan has a low soil fertility levels in various limiting factors, such as: poor content of organic material, so as to improve soil fertility with fertilizer needed organic fertilizer derived from compost or manure. Cation exchange capacity values are quite high up (10,4-17,36 me/100 g), so the land can only be used for the development of cash crops or plantation crops. Most of the land in Sangatta acidic, with high Al saturation, to reduce the acidity of the soil can be done by or with the accumulation Calcification phospat (element P) and $\mathrm{KCl}$.
\end{abstract}

Keywords: ultisol, fertility, soil management

\section{PENDAHULUAN}

Tanah utisol merupakan salah satu jenis tanah di Indonesia yang mempunyai sebaran terluas, yaitu mencapai 45.794 .000 hektar atau hampir $25 \%$ dari total seluruh daratan Indonesia ${ }^{(1)}$. sebaran terluas terdapat di Kalimantan yaitu sekitar 21.938.000 hektar, dengan tingkat produktivitas lahan sangat rendah.

Tanah ultisol memiliki kendala yang cukup berat apabila akan dimanfaatkan sebagai lahan budidaya tanaman pangan atau tanaman semusim lainnya. Menurut Tejoyuwono, N. ${ }^{(2)}$, segala persoalan yang muncul dalam tanah ultisol bersumber pada sejarah pembentukannya. Tanah ultisol dibentuk oleh proses pelapukan dan pembentukan tanah yang sangat intensif karena berlangsung dalam lingkungan iklim tropika dan subtropika yang bersuhu panas dan bercurah hujan tinggi.

Pada umumnya tanah ultisol mempunyai potensi keracunan Al dan miskin kandungan bahan organik. Tanah ini juga miskin kandungan hara lainnya terutama $P$ dan kation-kation dapat tertukar lainnya, seperti $\mathrm{Ca}, \mathrm{Mg}, \mathrm{Na}$ dan K, kadar Al tinggi, kapasitas tukar kation (KTK) rendah, dan peka terhadap erosi ${ }^{(1)}$. Pada umumnya tanah ultisol belum ditangani dengan baik. Dalam skala besar tanah ini dimanfaatkan untuk perkebunan kelapa sawit, karet dan hutan tanaman industri. Tetapi pada tingkat petani dengan alasan faktor ekonomi menjadikan salah satu penyebab tidak terkelolannya tanah utisol dengan baik. Oleh karena itu harus dapat diberikan solusi berupa inovasi teknologi yang dapat meningkatkan produktivitas tanah ultisol. 
Selain bermasalah terhadap kandungan kimia tanah, ultisol mempunyai kerentanan terhadap bahaya erosi, sehingga menyebabkan resiko terhadap erosi meningkat, berarti bahwa simpanan kesuburan tanah berada pada kedudukan yang paling mudah tererosi.

Menurut Tejoyuwono, N. ${ }^{(3)}$, untuk menghadapi tanah dengan kemampuan rendah seperti tanah ultisol, terdapat dua sistem pemanfaatan yang dapat dipilih, yaitu:

1. Membenahi kemampuan tanah, sehingga sepadan dengan jenis pemanfaatan atau bentuk penggunaan lahan yang diinginkan

2. Memilih jenis pemanfaatan atau bentuk penggunaan yang dapat diadaptasikan pada kemampuan asli tanah.

Untuk menjawab problimatika yang dihadapi terhadap kendala pada tanah ultisol, maka diperlukan terobosan teknologi yang cocok untuk diterapkan pada kawasan iklim tropika basah dengan tingkat kesuburan tanah rendah.

\section{TUJUAN}

Kegiatan penelitian ini dimaksudkan untuk mengetahui tingkat kesuburan tanah utisol pada lahan penambangan batubara di Kabupaten Sangatta dan solusi peningkatan kesuburan tanah untuk menunjang usahatani.

\section{METODOLOGI}

Data yang dikumpulkan dalam studi ini meliputi data sekunder dan primer. Data sekunder yang diperlukan antara lain data iklim, topografi, geohidrologi, tata guna lahan, dan data lapangan lainnya. Data primer diperoleh melalui analisis kualitas tanah secara laboratorium.

Sampel tanah diambil pada lahan yang masih virgin dan lahan bekas tambang yang sudah direhabilitasi. Parameter tanah yang diukur antara lain: $\mathrm{pH}$ tanah, Kapasitas
Tukar Kation (KTK), kadar Nitrogen (N-Total), P2O5 (P-tersedia), K2O (K dapat ditukar), struktur tanah dan parameter tanah lainnya. Pengambilan tanah dilakukan dengan menggunakan bor tanah pada kedalaman 0 $20 \mathrm{~cm}, 20-60 \mathrm{~cm}$. Sampel tanah asli (virgin) diambil di dua lokasi yaitu hutan AB 103 di Sangata dan hutan Bengalon, sedang jumlah tanah bekas penambangan yang telah direhabilitiasi diambil dari 11 titik sampel, yang lokasinya tersebar diseluruh wilayah konsensi tambang batubara Sangatta.

Pengambilan sampel tanah dilakukan dilakukan pada bulan 20 - 26 Oktober 2008, kemudian sampel tanah tersebut dianalisa laboratorium di Laboratorium Tanah, Fakultas Pertanian, Universitas Mulawarman, Kalimantan Timur.

\section{HASIL DAN PEMBAHASAN}

Analisis kualitas lahan ini mencakup juga analisis kandungan hara yang potensial maupun untuk mendukung pertumbuhan tanaman. Berdasarkan hasil analisis laboratorium terhadap sampel tanah (Tabel 1), dapat diuraikan sebagai berikut:

\subsection{Unsur Primer}

\section{1) Kemasaman Tanah (pH)}

$\mathrm{pH}$ tanah dapat mempengaruhi ketersediaan hara tanah dan bisa menjadi faktor yang berhubungan dengan kualitas tanah. $\mathrm{pH}$ sangat penting dalam menentukan aktivitas dan dominasi mikroorganisme tanah yang berhubungan dengan proses-proses yang sangat erat kaitannya dengan siklus hara, penyakit tanaman, dekomposisi dan sintesa senyawa kimia organik dan transpor gas ke atmosfir oleh mikroorganisme, seperti metan.

Lahan bekas tambang yang telah direhabilitasi $\mathrm{pH}$ tanahnya berkisar 4,4-5,3, mengindikasikan bahwa tanah tergolong sangat masam - masam, sedang $\mathrm{pH}$ tanah pada kawasan hutan (tanah asli) pHnya berkisar antara 4,2 - 4,3 tergolong tanah sangat masam. 
Dari data tersebut di atas dapat diketahui bahwa tanah di daerah penelitian pada umumnya masam hingga sangat masam ( $\mathrm{pH}$ 4.0-5.3), hal ini membuktikan bahwa jenis tanah utisol di Sangatta terbentuk bukan dari batu gamping yang pada umumnya reaksi netral hingga agak masam ( $\mathrm{pH} 6,50-6,80)$. Kemasaman lahan tambang biasanya dipengaruhi juga oleh ada tidaknya pyrit (FeS).

\section{2) Bahan Organik dan Total Nitrogen}

Penambahan bahan organik kedalam tanah lebih kuat pengaruhnya kearah perbaikan sifat-sifat tanah, khususnya untuk meningkatkan unsur hara di dalam tanah.

Kandungan bahan organik di wilayah studi umumnya rendah $(0,67-1,57) \%$ akibat dari pencucian basa berlangsung intensif, dan sebagian terbawa erosi. Pada tanah yang mepunyai horizon kandik, kesuburan alami hanya ditentukan pada bahan organik di lapisan atas, sehingga kapasitas pertukaran kation hanya tergantung pada kandungan bahan organik dan fraksi liat(3). Oleh karena itu untuk meningkatkan produktivitas tanah hanya dapat dilakukan melalui perbaikan tanah melalui pemupukan dan pemberian bahan organik.

Bahan organik adalah merupakan sumber $\mathrm{N}$ utama di dalam tanah dan berperan cukup besar dalam proses perbaikan sifat fisika, kimia dan biologi tanah. Kadar $\mathrm{N}$ tanah biasanya dikategorikan sebagai indikator untuk menentukan dosis pemupukan Urea. Fungsi nitrogen dalam tanah adalah untuk memperbaiki pertumbuhan vegetatif tanaman. Tanaman yang tumbuh pada tanah yang cukup $\mathrm{N}$, berwarna lebih hijau. Gejala kekurangan $\mathrm{N}$, tanaman tumbuh kecil atau kerdil, pertumbuhan akar terbatas dan daunnya kuning. Kadar $\mathrm{N}$ total tanah wilayah studi tergolong sangat rendah denagn kisaran antara 0,04-0,16 persen. Namun khusus untuk tanah yang masih asli, $\mathrm{N}$ total tanah lebih tinggi dibandingkan dengan tanah yang sudah digarap atau terbuka.

\section{3) C/N Ratio}

$\mathrm{C} / \mathrm{N}$ rasio berfungsi untuk mengatur apakah bahan organik dalam kondisi cepat hancur tatu sulit hancur. Bahan organik dapat berbentuk halus dan kasar. Bahan organik halus mempunyai kadar $\mathrm{N}$ tinggi dengan $\mathrm{C} / \mathrm{N}$ ratio rendah, sedangkan bahan organik kasar mempunyai $\mathrm{N}$ rendah dengan $\mathrm{C} / \mathrm{N}$ ratio tinggi. Faktor yang mempengaruhi pengancuran bahah organik antara lain suhu, kelembaban, tata udara tanah, pengolahan tanah, $\mathrm{pH}$ dan jenis bahan organik (4).

Nilai $\mathrm{C} / \mathrm{N}: 12-14$ adalah merupakan nilai tengah, artinya kandungan bahan organiknya cukup baik apabila digunakan sebagai bahan pendukung pertumbuhan tanaman. Nilai kurang dari 11 artinya bahan organiknya sudah sangat melapuk dalam tanah dan sebaiknya ditambahkan bahan yang mengandung organik, seperti kompos atau kotoran ternak. Sedang nilai diatas 15 berarti bahwa bahan organik belum terdekomposisi sehingga perlu waktu untuk mendukung pertumbuhan tanaman.

$\mathrm{C} / \mathrm{N}$ rasio tanah di lahan bekas pertambangan di Kabupaten Sangatta berkisar antara $10-15$, nilai ini tergolong sedang sampai rendah.

\section{4) Kandungan $P$ dan $K$ Tersedia}

Fosfor $(P)$ merupakan unsur hara esensiil bagi tanaman. Tidak ada unsur lain yang dapat menggantikan fungsinya di dalam tanaman, sehingga tanaman harus mendapatkan unsur hara $P$ secara cukup untuk pertumbuhannya. Fungsi penting fosfor di dalam tanaman yaitu dalam proses fotosintesis, respirasi, transfer dan penyimpanan energi, pembelahan dan pembesaran sel serta proses-proses yang lainnya.

Ketersediaan $\mathrm{P}$ dalam tanah bagi tanaman dipengaruhi oleh kemasaman tanah. Ketersediaan optimum dari unsur hara ini bagi tanaman diperoleh pada $\mathrm{pH}$ $5,5-7,0$. Bentuk ion $\mathrm{P}$ yang terdapat dalam tanah tergantung dari $\mathrm{pH}$ larutan tanah, bila 
tanah bereaksi basa ion $\mathrm{HPO}_{4} 2$ - merupakan ion $\mathrm{P}$ yang dominan, dengan menurunnya $\mathrm{pH}$ tanah, bentuk $\mathrm{H}_{2} \mathrm{PO}_{4}$ - dan $\mathrm{HPO}_{4} 2$ - akan dijumpai dalam larutan tanah, sedangkan apabila keadaan kemasaman bertambah $\mathrm{H} 2 \mathrm{PO}_{4}-$ akan semakin dominan. Tanaman mengambil fosfor dari dalam larutan tanah dalam bentuk ortho fosfat primer $\left(\mathrm{H}_{2} \mathrm{PO}_{4}\right)$, mekanismenya melalui proses difusi. Kecepatan penyediaannya dari tanah ke akar dipengaruhi oleh koefisien difusi, kosentrasi hara fosfor dalam larutan tanah, dan kapasitas penyangga tanah.

Kandungan $\mathrm{P}$ tersedia (P-Bray 1$)$ di pertambangan batu bara KPC pada tanah lapisan $0-20 \mathrm{~cm}$ bervariasi sangat rendah sampai sangat tinggi (12,00 - 25 ppm P2O5), dan sangat rendah sampai tinggi untuk tanah lapisan $20-60 \mathrm{~cm}(11,00-30,00$ ppm P2O5), dimana rata-rata kandungan $P$ tersedia bagian bawah relatif lebih rendah dibandingkan tanah lapisan atas. Hal ini memberi indikasi bahwa sumber $\mathrm{P}$ diantaranya berasal dari bahan organik dari batuan fosfat tanah (apathite).

Pada $\mathrm{pH}$ kurang dari 5,5 ion fosfat akan diikat oleh Fe dan Al sebagai senyawa yang tidak larut dalam air, sedangkan diatas $\mathrm{pH}$ 7,0 akan bereaksi dengan $\mathrm{Ca}$ dan $\mathrm{Mg}$ membentuk senyawa yang tidak larut dalam air dan menjadi tidak tersedia bagi tanaman. Hasil analisis laboratorium menunjukkan bahwa kandungan $\mathrm{P}$ dalam tanah wilayah studi dengan ekstraks $\mathrm{HCl} 25$ persen adalah berkisar antara $6-30 \mathrm{mg} / 100 \mathrm{~g}$. Nilai ini tergolong sangat rendah sampai sedang. Dengan menggunakan ekstrak Bray diperoleh hasil yang sama yaitu, kandungan fosfor dalam tanah berkisar antara $6-21$ ppm. Nilai ini tergolong kategori sangat rendah hingga sedang.

Kalium merupakan unsur hara ketiga setelah $\mathrm{N}$ dan $\mathrm{P}$ yang dibutuhkan tanaman dalam jumlah banyak dan berperan penting dalam proses fotosintesa, pembentukan karbohidrat dan protein. Pemupukan kalium pada lahan pertanian kering baik padi maupun jagung serta umbi-umbian menunjukkan hasil yang nyata, apabila pupuk nitrogen dan fosfor juga diberikan dalam jumlah yang cukup, tetapi bila terjadi konsumsi kalium yang berlebihan, maka konsentrasi kalium dalam jaringan tumbuhan meningkat, akibatnya translokasi kation lain terutama $\mathrm{Mg}$ akan terganggu sehingga terjadi penurunan kadar $\mathrm{Mg}$ dalam daun sedemikian rendahnya sehingga fotosintesa akan terganggu. ${ }^{(5)}$ Sebaliknya bila kadar $\mathrm{Mg}$ dalam tanah dalam jumlah tinggi, maka kadar kalium yang tersedia bagi tanaman akan menurun, karena difiksasi oleh koloid tanah atau tercuci bersama air drainase (curah hujan tinggi).

Hasil analisis laboratorium menunjukkan bahwa kandungan atau kadar kalium dalam tanah wilayah studi tergolong sedang hingga sangat tinggi. Nilainya berkisar antara $18-42$ ppm dengan ekstraksi Morgan, sedangkan dengan ekstraksi $\mathrm{HCl}$ kandungan kalium dalam tanah wilayah studi tergolong sangat rendah hingga sedang. Nilainya berkisar antara $4-25 \mathrm{mg} / 100 \mathrm{~g}$. Dalam bentuk kation $\mathrm{K}$, kandungan kalium tergolong sangat rendah sampai rendah dan nilainya berkisar antara 0,07-0,26 meg/100g. Nilai kation ini merupakan nilai yang mempengaruhi nilai KTK tanah di wilayah studi.

\subsection{Unsur hara sekunder}

\section{1) Kalsium (Ca)}

Kation Ca merupakan kalsium yang berada dalam kompleks jerapan tanah dan nilai ini akan mempengaruhi nilai KTK dan kejenuhan basa (KB) tanah wilayah studi. Kandungan kalsium pada tanah wilayah studi tergolong sangat rendah sampai sedang dan nilainya berkisar antara $0,11-6,25$ $\mathrm{meg} / 100 \mathrm{~g}$.

\section{2) Magnesium (Mg)}

Seperti halnya kation $\mathrm{Ca}$, kation $\mathrm{Mg}$ juga merupakan kation yang berada dalam kompleks jerapan tanah dan nilai ini akan mempengaruhi nilai KTK dan kejenuhan 
basa (KB), kandungan magnesium pada tanah di wilayah studi tergolong sedang hingga tinggi dan nilainya berkisar antara $1,09-7,54 \mathrm{meg} / 100 \mathrm{~g}$.

\section{3) Sulfur (S)}

Sulfat terlarut tanah wilayah studi berkisar antara 0,001-0,029 persen, nilai ini tergolong sangat kecil. Apabila dihitung berdasarkan kebutuhan kapur untuk menetralisir pyrit dalam tanah, maka kapur dibutuhkan untuk menetralisir tanah yang mengandung pyrit. Besarnya nilai kebutuhan kapur dihitung berdasarkan standard 31,25 mg CaCO ${ }_{3}$ untuk setiap $1 \%$ kandungan pyrite dalam 1000 gram tanah. Jadi berdasarkan perhitungan ini dapat ditentukan kebutuhan kapur untuk menetralisir kandungan pyrite dalam tanah untuk setiap hektar lahan pasca tambang PT. KPC. Diketahui bahwa berat jenis tanah wilayah studi berkisar antara 1,0 $-1,61 \mathrm{~g} / \mathrm{cm}^{2}$. Berdasarkan perhitungan, maka satu hektar lahan dibutuhkan kapur hanya sebanyak 30-45 kg kapur untuk mentralisir kandungan pyrit tanah wilayah studi.

\subsection{Unsur Hara Mikro}

Unsur hara mikro yang dianalisis dari contoh tanah di wilayah studi adalah unsur Fe dan Mn. Nilai ini akan mencirikan apakah di wilayah studi termasuk dalam tanah masam atau tanah yang dipengaruhi oleh ada tidaknya pyrit akibat pertambangan batubara. Bila kandungan Fe dan Mn tinggi artinya faktor $\mathrm{pH}$ akan mempengaruhi tinggi rendahnya unsur-unsur tersebut.

\section{1) Besi (Fe)}

Diketahui bahwa jumlah $\mathrm{Fe}$ dalam tanah akan mempengaruhi ketersediaan hara fosfat untuk pertumbuhan tanaman. Bila Fe berkadar tinggi maka fosfat akan terikat dengan $\mathrm{Fe}$ dan membentuk ikatan yang tidak dapat larut dalam air, akibatnya fosfat tidak tersedia untuk pertumbuhan tanaman. Nilai $\mathrm{Fe}$ atau kandungan besi dalam tanah di wilayah studi berkisar antara $40-58$ ppm, nilai ini tergolong tinggi sampai sangat tinggi.

\section{2) Mangan $(\mathrm{Mn})$}

Unsur mangan merupakan unsur yang mengganggu pertumbuhan tanaman, dan apabila kandungan dalam tanah jumlahnya tinggi, maka unsur ini akan berasosiasi dengan Fe membentuk konkresi besi dan akan mengikat fosfor yang ada dalam tanah dan berakibat fosfor tidak tersedia untuk pertumbuhan tanaman. Nilai kandungan unsur Mn dalam tanah di wilayah studi berkisar antara $3-25$ ppm dan nilai ini tergolong sangat rendah hingga sedang.

\section{3) Kejenuhan Basa (KB) dan}

\section{Kapasitas Tukar Kation}

Nilai Kejenuhan Basa (KB) tanah merupakan persentase dari total KTK yang diduduki oleh kation-kation basa, yaitu $\mathrm{Ca}, \mathrm{Mg}, \mathrm{Na}$, dan K. Nilai KB ini sangat penting dalam penggunaannya untuk pertimbangan-pertimbangan pemupukan dan memprediksi kemudahan unsur hara tersedia bagi tanaman. Kejenuhan basa menunjukkan perbandingan antara jumlah kation-kation basa dengan jumlah semua kation (kation basa dan kation asam) yang terdapat dalam kompleks jerapan tanah. Jumlah maksimum kation yang dapat diserap tanah menunjukkan besarnya nilai kapasitas tukar kation tanah tersebut. Kation-kation basa umumnya merupakan unsur hara yang diperlukan tanaman. Disamping itu basabasa umumnya mudah tercuci, sehingga tanah tersebut belum banyak mengalami proses pencucian dan merupakan tanah yang subur. Kejenuhan basa berhubungan erat dengan $\mathrm{pH}$ tanah, dimana tanah dengan $\mathrm{pH}$ rendah mempunyai kejenuhan basa rendah, sedangkan tanah dengan $\mathrm{pH}$ tinggi mempunyai kejenuhan basa yang tinggi pula. Kejenuhan basah tanah di wilayah studi berkisar antara 13-89 persen, nilai ini tergolong rendah sampai sangat tinggi.

Kation-kation yang diikat atau diadsorpsi oleh koloid tanah dapat diganti oleh kation-kation lain, proses ini disebut pertukaran kation. Jumlah total kation di dalam tanah yang dapat dipertukarkan 
disebut pertukaran tukar kation (KTK). Tanah-tanah yang mempunyai kadar liat/ koloid lebih tinggi dan/atau kadar bahan organik tinggi mempunyai KTK lebih tinggi dibandingkan dengan tanah yang mempunyai kadar liat rendah (tanah pasiran) dan kadar bahan organik rendah. Proses pertukaran kation sangat penting untuk diketahui oleh pemerhati pertanian karena sangat terkait dengan pengelolaan tanah dalam hubungannya dengan pemupukan dan pengapuran serta proses serapan unsur hara oleh akar tanaman.

Kapasitas tukar kation (KTK) merupakan sifat kimia tanah yang sangat erat hubungannya dengan kusuburan tanah. Tanah dengan KTK tinggi mampu menyerap dan menyediakan unsur hara lebih baik dari pada tanah dengan KTK rendah. Karena unsur-unsur tersebut berada dalam kompleks jerapan tanah, maka unsur-unsur hara tersebut tidak mudah hilang atau tercuci oleh air. Tanah-tanah dengan kandungan bahan organik atau dengan kadar liat tinggi mempunyai KTK lebih tinggi dari pada tanahtanah dengan kadar bahan organik rendah atau tanah berpasir.

Pada umumnya nilai kejenuhan basa tinggi dan mempunyai kapasitas pertukaran kation $(\mathrm{KTK})<16 \mathrm{cmol} / \mathrm{kg}$, yaitu salah satu ciri tanah ultisol yang mempunyai horizon kandik. Kapasitas tukar kation pada tanah dari granit, sedimen, dan batu tufa pada umumnya mempunyai nikai KTK rendah yaitu masing-masing berkisar antara 2.90$7.50 \mathrm{cmol} / \mathrm{kg}, 6,11-13,68 \mathrm{cmol} / \mathrm{kg}$ dan $6.10-$ $6.80 \mathrm{cmol} / \mathrm{kg}$, sedang yang dari bahan volkan andesit dan batu gamping tergolong tinggi (> $17 \mathrm{cmol} / \mathrm{kg}$ ).

Nilai KTK di wilayah studi, tanah lapisan atas $0-20 \mathrm{~cm}$ tergolong rendah $(10,4-17,36 \mathrm{me} / 100 \mathrm{~g})$ dan pada lapisan $20-60 \mathrm{~cm}$ juga tergolong rendah $(10,5$ - 17,12 me/100 g). KTK tanah lapisan 0 $20 \mathrm{~cm}$ yang paling rendah terdapat pada lokasi Sangatta (sempadan sungai), yang bertekstur liat berlempung (silt loam), yaitu sebesar 2,24 me/100 g. Rendahnya KTK tanah di lokasi tersebut secara langsung dan tidak langsung dipengaruhi oleh reaksi tanah yang sangat masam, kandungan kejenuhan Al tinggi yang rendah, dan kandungan $\mathrm{Mn}$ yang rendah. Kejenuhan Basa (KB) secara relatif ditentukan oleh jumlah kation basa dan reaksi tanah $(\mathrm{pH})$. Hubungan KB dengan $\mathrm{pH}$ tanah pada umumnya positif, yakni $\mathrm{pH}$ tanah se-makin tinggi KB tanah juga semakin tinggi, begitu pula sebaliknya. Rata-rata KB tanah di Sangatta bervariasi dari rendah (33\%) sampai sangat tinggi (75\%).

KTK tanah menggambarkan kationkation tanah seperti $\mathrm{Ca}, \mathrm{Mg}, \mathrm{Na}$, dan $\mathrm{K}$ dapat ditukar dan diserap oleh perakaran tanaman. KTK tanah di wilayah studi berkisar antara 10,4 - 18,9 meg/100g dan nilai ini tergolong rendah sampai sedang.

\section{4) Kejenuhan $\mathrm{Al} 3+$ dan $\mathrm{H}+$}

Disamping kejenuhan basa ada pula nilai saingan lain yaitu kejenuhan $\mathrm{Al}$ dan $\mathrm{H}$. Nilai ini menunjukkan suatu kondisi dimana kompleks jerapan tanah dipenuhi oleh Al atau oleh basa-basa dapat ditukar. Bila tanah dipenuhi oleh basa-basa terlarut, maka kompleks jerapan tanah akan mampu memberikan unsur hara yang cukup bagi pertumbuhan tanaman, tetapi sebaliknya bila kompleks jerapan tanah dipenuhi oleh Al dan $\mathrm{H}$, maka tanah akan bersifat masam dan nilai Fe dan Mn akan tinggi dan tanaman tidak dapat mampu tumbuh karena keracunan Al dan Fe serta Mn, sehingga tanaman tumbuh tidak normal dan kerdil. Jadi nilai kejenuhan $\mathrm{Al}$ dan $\mathrm{H}$ selalu berlawanan dengan nilai kejenuhan basa. Nilai kejenuhan asam di Sangatta berkisar antara $2-35$ persen, dan nilainya selalu terbalik dengan nilai kejenuhan basa.

\section{5) Pyrit (FeS)}

Kandungan pyrit (FeS) merupakan indikator yang mencirikan tanah-tanah masam atau tanah terkontaminasi dengan FeS yang teroksidasi karena terpapar dengan udara besar atau adanya air yang mengalir pada 
lapisan tanah sehingga tanah menjadi bersifat sangat masam dengan $\mathrm{pH}$ 2-3. Kadungan pyrit tanah di wilayah studi berkisar antara $0,12-0,62$ persen, nilai tersebut tergolong sangat rendah hingga rendah.

\section{SOLUSI PENINGKATAN KESUBURAN}

\subsection{Pengapuran}

Untuk mengatasi kendala kemasaman dan kejenuhan Al yang tinggi dapat dilakukan dengan pengapuran. Pemberian kapur bertujuan untuk meningkatkan $\mathrm{pH}$ tanah dari sangat masam atau masam ke $\mathrm{pH}$ mendekati netral atau netral, serta menurunkan kadar Al. Pemberikan kapur juga dapat meningkatkan kadar $\mathrm{Ca}$ dan kejenuhan basa. Pemberian kapur yang setara dengan $1 \times$ Aldd dapat menurunkan kejenuhan Al dari $87 \%$ menjadi $<20 \%{ }^{(1)}$.

Karena setiap jenis tanaman (terutama tanaman pangan) mempunyai toleransi yang berbeda terhadap kejenuhan $\mathrm{Al}$, maka semakin besar prosentase kejenuhan $\mathrm{Al}$ dalam tanah akan membutuhkan semakin banyak kapur.

Pemberian kapur diharapkan akan dapat mengatasi masalah kemasaman tanah dan juga menjamin tanaman dapat bertahan hidup dan berproduksi bila terjadi kekeringan. Akan tetapi karena di sebagian besar wilayah Kalimantan ketersedian kapur sangat terbatas, maka dianjurkan agar pengapuran sebaiknya dilakukan hanya untuk wilayah yang mempunyai $\mathrm{pH}<5$.

\subsection{Pemupukan Fosfat dan Kalium}

Pemupukan fosfat merupakan salah satu cara mengelola lahan pertambangan batubara Sangatta yang pada umumnya memiliki tanah berjenis ultisol. Penggunaan pupuk $P$ dari TSP akan lebih efisien daripada $\mathrm{P}$ alami, dan pupuk K diberikan dalam bentuk $\mathrm{KCl}$ dengan takaran 100-130 kg KCl/hektar.

\subsection{Penambahan Bahan Organik}

Tanah ultisol umumnya peka terhadap erosi dan mempunyai pori aerasi serta indeks stabilitas yang rendah sehingga mudah tererosi dan mudah padat. Akibatnya, pertumbuhan akar tanaman akan terhambat karena daya tembus akar ke dalam tanah menjadi berkurang. Selain dapat meningkatkan kesuburan tanah, bahan organik juga memiliki peran yang penting dalam memperbaiki sifat fisik tanah. Bahan organik dapat meningkatkan agregasi tanah, memperbaiki aerasi dan perkolasi, serta membuat struktur tanah menjadi lebih remah dan mudah diolah. Bahan organik melalui fraksi-fraksinya mempunyai pengaruh nyata terhadap pencucian hara.

Kondisi tanah pada pertambangan batubara di Sangatta mengalami perubahan fisik yang cukup berat. Kerusakan ini terutama terjadi pada perubahan struktur dan kemantapan agregat tanah ketika dilakukan pemindahan lapisan tanah. Bahan organik tanah dapat memperbaiki kembali struktur tanah dan kesarangan tanah yang ada dan merangsang kembali akitivitas mikroorganisme tanah. Agregat tanah terbentuk diawali dengan suatu mekanisme yang menyatukan partikel-partikel primer (pasir, debu dan liat) membentuk gumpalan atau kelompok dan dilanjutkan dengan adanya suatu komponen yang bertindak sebagai pengikat partikelpartikel tanah agar partikel-partikel tanah ini menjadi lebih kuat (sementasi).

Selain fungsinya dalam memperbaiki sifat fisik dan kimia tanah, bahan organik tanah juga menyediakan unsur nitrogen $(\mathrm{N})$ untuk kebutuhan mikroorganisme tanah, menciptakan kelembaban dan suhu tanah yang memadai bagi aktivitas mikroorganisme tanah. Aktivitas mikroorganisme yang tinggi di dalam tanah akan membantu mempercepat proses dekomposisi dan mineralisasi bahan organik sehingga kebutuhan hara di dalam tanah dapat cepat tersedia.

Berbeda dengan bahan anorganik atau pupuk buatan, bahan organik merupakan bahan pembenahan tanah yang ramah lingkungan dan tidak mencemari tanah dan 
air. Dengan demikian, kegiatan pertanian organik merupakan salah satu cara untuk membatasi ketergantungan akan pupuk anorganik dan bahan kimia pertanian.

Untuk menghindari terjadinya erosi dan meningkatkan kandungan unsur hara tanah dalam timbunan tanah bagian atas (top soil dan sub soil) yang dipindahkan ke tempat penimbunan sementara, dianjurkan agar tempat penimbunan sementara itu ditanami dengan tanaman penghasil pupuk hijau atau menambahkan bahan organik dari pupuk kandang maupun sisa-sisa tanaman lainnya. Hal ini akan dapat memperbaiki sifat fisik tanah seperti tersedianya pori air, indeks stabiltas agregat, dan kepadatan tanah. Jika dibandingkan dengan memberikan pupuk kandang berdosis 10 ton/ha akan sangat sulit dilakukan oleh petani, pemberian bahan organik, baik dengan cara menanami secara sengaja maupun dengan menambahkan sisa tanaman akan lebih mudah dilakukan dan tidak akan menimbulkan masalah bagi lingkungan.

Penambahan bahan organik dapat pula dilakukan melalui pertanian lorong (alley cropping). Selain pangkasan tanaman dapat menjadi sumber bahan organik tanah, pola pertanian lorong juga dapat mengendalikan erosi. Bagian-bagian tanaman seperti daun, batang atau ranting kering, bila jatuh ke tanah akan mengalami dekomposisi dan menghasilkan bahan organik. Perakaran tanaman di dalam tanah dan berbagai mikroorganisme tanah yang telah mati merupakan sumber bahan organik tanah. Kontribusi bahan organik terhadap sifat fisik, kimia dan biologi tanah antara lain memperbaiki struktur tanah dan porositas tanah, menurunkan permeabilitas tanah pada tanah berpasir, dan meningkatkan permeabilitas tanah pada tanah berliat. Bahan organik tanah akan meningkatkan daya menahan air, sehingga kemampuan tanah untuk menyediakan air menjadi lebih banyak dan kelengasan air tanah tetap terjaga, atau dengan kata lain untuk meningkatkan kesuburan tanah ultisol dapat dengan cara back to nutural.

Secara kimiawi bahan organik tersusun dari $44 \%$ Karbon, $8 \%$ Hidrogen, $40 \%$ Oksigen dan $8 \%$ bahan mineral. Kandungan hara bahan organik jenis leguminosa sebesar 2,38\% Nitrogen, 0,21\% Phospor, 1,13\% Kalium, 1,47\% Calsium, 0,38\% Magnesium, 0,24\% Natrium, 22\% Sulfat dan $0,38 \%$.

\section{KESIMPULAN}

Secara umum tanah utisol mempunyai kendala untuk pengembangan usahatani, hal tersebut dikarenakan:

1) Tanah utisol pada tambang batubara Sangatta, mempunyai nilai KTK dari sedang sampai tinggi $(10,4-$ $17,36 \mathrm{me} / 100 \mathrm{gram})$, tanah tersebut dapat dimanfaatkan untuk berbagai usahatani, terutama budidaya tanaman keras atau tanaman perkebunan

2) Miskin kandungan bahan organik, sehingga untuk meningkatkan kesuburan tanah, dibutuhkan pemupukan pupuk organik

3) Tanah bersifat asam, dengan kejenuhan Al tinggi, sehingga tanaman tidak dapat tumbuh secara normal. Untuk mengurangi keasaman tanah dapat dilakukan dengan pengapuran atau dengan pemupukan phospat (unsur $\mathrm{P}$ ) dan $\mathrm{KCl}$ 


\section{DAFTAR PUSTAKA}

1. Prasetyo, B.H., dan Suriadikarta, D.A., Karakteristik, Potensi, dan Teknologi Pengelolaan Tanah Ultisol untuk Pengembangan Pertanian Lahan Kering di Indonesia. Balai Besar Penelitian dan Pengembangan Sumberdaya Lahan. Bogor.

2. Tejoyuwono, N., (1995). Gatra Lingkungan Kegiatan Pertanian. Seminar Nasional tentang Upaya Pengelolaan Lingkungan dan Upaya
Pemantauan Lingkungan. Lembaga Pendidikan Kejuruan WANA WIYATA dengan Bapedal Pusat. Yogyakarta, 24-25 Januari 1995.

3. (1986). Ultisol, Fakta dan Implikasi Pertaniannya. Bulletin Pusat Penelitian Marihat. No. 6.

4. Zeng-Yei Hsru and Zueng-Sang Chen (2001). Quantifying Soil Hydromorphology of a Rice-Growing Utisol Toposequence in Taiwan. Soil Science of America Journal 65:270-278 
Tabel 1. Hasil Analisa Kualitas Tanah pada Areal Pasca Tambang Sangatta

\begin{tabular}{|c|c|c|c|c|c|c|c|c|c|c|c|c|c|c|c|c|c|c|c|c|c|c|}
\hline \multirow{3}{*}{ No. } & \multirow{3}{*}{ Lokasi } & \multirow{3}{*}{$\mathrm{pH}$} & \multirow{2}{*}{\begin{tabular}{|c|}
$\mathrm{C}$ \\
organik
\end{tabular}} & \multirow{3}{*}{ N Total } & \multirow{3}{*}{$\mathrm{CN}$} & \multirow{2}{*}{$\begin{array}{l}\mathrm{P}_{2} \mathrm{O}_{5} \\
\text { Bray }\end{array}$} & \multirow{2}{*}{$\begin{array}{c}\mathrm{K}_{2} \mathrm{O} \\
\text { Morgan }\end{array}$} & \multirow{2}{*}{$\begin{array}{l}\mathrm{P}_{2} \mathrm{O}_{5} \\
\mathrm{HCl}\end{array}$} & \multirow{2}{*}{$\begin{array}{l}\mathrm{K}_{2} \mathrm{O} \\
25 \\
\% \\
\end{array}$} & \multicolumn{4}{|c|}{$\begin{array}{c}\text { Kation Basa } \\
\quad(\mathrm{pH} 7)\end{array}$} & \multirow[t]{3}{*}{ KTK } & \multirow{2}{*}{\multicolumn{2}{|c|}{\begin{tabular}{c|}
$\mathrm{Fe}$ \\
Mangan
\end{tabular}}} & \multicolumn{2}{|c|}{$\begin{array}{l}\text { Kat. } \\
\text { Asam }\end{array}$} & \multirow{2}{*}{$\begin{array}{c}\text { Kej. } \\
\text { Basa }\end{array}$} & \multirow{2}{*}{$\begin{array}{c}\text { Kej. } \\
\text { Al. }\end{array}$} & \multirow{2}{*}{ Pirit } & \multirow{2}{*}{$\mathrm{SO}_{4}$ larut } \\
\hline & & & & & & & & & & $\underset{++}{\mathrm{Ca}}$ & $\begin{array}{c}\mathrm{Mg} \\
+\end{array}$ & K & $\mathrm{Na}^{+}$ & & & & & & & & & \\
\hline & & & $\%$ & & & \multicolumn{2}{|c|}{$\mathrm{ppm}$} & \multicolumn{2}{|c|}{$\mathrm{mg} / 100 \mathrm{~g}$} & \multicolumn{4}{|c|}{$\operatorname{meg} / 100 \mathrm{~g}$} & & \multicolumn{2}{|c|}{ ppm } & \multicolumn{2}{|c|}{$\mathrm{meg} / 100 \mathrm{~g}$} & \multicolumn{4}{|c|}{$\frac{10}{10}$} \\
\hline 1 & Gajah Hitam $20 \mathrm{Cm}$ & 4,0 & 1,23 & 0,10 & 12 & 11 & 29 & 12 & 21 & 1.32 & 2.24 & 0.09 & 0.18 & 10.4 & 50 & 25 & 2.7 & 1.4 & 37 & 41 & 0.16 & 0.001 \\
\hline & Gajah Hitam $60 \mathrm{Cm}$ & 4,1 & 0,76 & 0,06 & 12 & 8 & 35 & 18 & 25 & 1.73 & 4.06 & 0.09 & 0.41 & 10.5 & 48 & 17 & 2.3 & 2.9 & 60 & 26 & 0.15 & 0.005 \\
\hline 2 & CPP Area $20 \mathrm{Cm}$ & 4,9 & 1,17 & 0,12 & 10 & 11 & 42 & 23 & 28 & 1.33 & 3.16 & 0.15 & 0.05 & 15.0 & 42 & 20 & 2.4 & 1.1 & 31 & 34 & 0.35 & 0.002 \\
\hline & CPP Area $60 \mathrm{Cm}$ & 4,6 & 0,67 & 0,08 & 9 & 8 & 19 & 23 & 8 & 1.01 & 5.14 & 0.17 & 0.12 & 15.0 & 42 & 15 & 2.3 & 1.3 & 43 & 27 & 0.06 & 0.003 \\
\hline 3 & AB $10320 \mathrm{Cm}$ & 5,3 & 1,57 & 0,16 & 10 & 11 & 22 & 20 & 10 & 6.25 & 2.59 & 0.20 & 0.03 & 15.6 & 41 & 14 & 0.1 & 0.1 & 58 & 1 & 0.09 & 0.004 \\
\hline & AB $10360 \mathrm{~cm}$ & 4,9 & 0,96 & 0,11 & 9 & 11 & 31 & 10 & 18 & 3.73 & 4.33 & 0.20 & 0.04 & 15.8 & 40 & 10 & 1.7 & 0.9 & 52 & 17 & 0.48 & 0.003 \\
\hline 4 & Sangata (Sungai) $20 \mathrm{Cm}$ & 5,0 & 0,66 & 0,09 & 7 & 11 & 33 & 6 & 18 & 5.06 & 7.47 & 0.21 & 0.10 & 18.9 & 50 & 3 & 0.1 & 0.1 & 68 & 1 & 0.62 & 0.006 \\
\hline & Sangata $60 \mathrm{Cm}$ & 4,8 & 1,35 & 0,13 & 10 & 10 & 24 & 26 & 15 & 1.60 & 2.17 & 0.13 & 0.16 & 15.4 & 55 & 18 & 3.0 & 1.8 & 26 & 42 & 0.10 & 0.003 \\
\hline 5 & Sangata $20 \mathrm{Cm}$ & 4,7 & 0,70 & 0,06 & 13 & 13 & 19 & 20 & 12 & 0.11 & 1.09 & 0.08 & 0.23 & 11.7 & 46 & 11 & 4.5 & 1.9 & 13 & 75 & 0.22 & 0.003 \\
\hline & Sangata $60 \mathrm{Cm}$ & 5,3 & 0,82 & 0,06 & 13 & 5 & 26 & 20 & 17 & 1.53 & 4.43 & 0.12 & 0.35 & 11.1 & 42 & 22 & 0.1 & 0.1 & 58 & 1 & 0.05 & 0.002 \\
\hline 6 & $\begin{array}{l}\text { Sangatta } \\
\text { (penggembalaan) } 20 \mathrm{Cm}\end{array}$ & 4,7 & 1,10 & 0,11 & 10 & 11 & 20 & 13 & 14 & 1.05 & 3.78 & 0.08 & 0.46 & 12.1 & 44 & 17 & 0.3 & 0.2 & 44 & 5 & 0.21 & 0.003 \\
\hline & Sangatta North $60 \mathrm{Cm}$ & 5,0 & 0,73 & 0,08 & 9 & 11 & 21 & 16 & 14 & 1.08 & 2.45 & 0.10 & 0.25 & 11.9 & 42 & 11 & 0.6 & 0.4 & 37 & 12 & 0.46 & 0.004 \\
\hline 7 & $\begin{array}{l}\text { Sangatta North (reklamasi) } \\
20 \mathrm{Cm}\end{array}$ & 4,6 & 0,81 & 0,06 & 13 & 14 & 28 & 12 & 13 & 1.29 & 1.75 & 0.26 & 0.38 & 11.20 & 46 & 15 & 2.0 & 1.2 & 33 & 35 & 0.48 & 0.003 \\
\hline & Sangatta North $60 \mathrm{Cm}$ & 5,6 & 0,74 & 0,06 & 13 & 5 & 26 & 11 & 11 & 1.53 & 3.15 & 0.14 & 0.29 & 11.44 & 40 & 12 & 1.5 & 1.0 & 49 & 23 & 0.01 & 0.004 \\
\hline 8 & Sangatta North Agate $20 \mathrm{Cm}$ & 4,7 & 0,85 & 0,07 & 12 & 9 & 24 & 24 & 16 & 2.09 & 5.23 & 0.12 & 0.27 & 11.60 & 45 & 20 & 1.1 & 0.9 & 57 & 13 & 0.23 & 0.005 \\
\hline & Sangatta North Agate $60 \mathrm{Cm}$ & 4,8 & 0,90 & 0,08 & 11 & 7 & 28 & 25 & 19 & 1.17 & 4.15 & 0.15 & 0.08 & 15.00 & 45 & 17 & 0.5 & 0.3 & 37 & 9 & 0.16 & 0.006 \\
\hline 9 & Sangatta I & 5 & 0,0 & 0,09 & 11 & 0 & 2 & 12 & 14 & 3. & 3.87 & 0. & 0.07 & 15. & 46 & 22 & 0.2 & 0.1 & 50 & 2 & 0.05 & 0.012 \\
\hline & & & & & 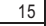 & 1 & & 30 & 16 & & 3.46 & & & & 46 & 19 & & 0.1 & & & 25 & \\
\hline 10 & Bengalon $20 \mathrm{Cm}$ & 4,4 & 0,85 & 0, & 11 & 15 & 2 & 16 & 12 & 4 & 5.90 & 0.12 & 0.07 & 17.3 & 45 & 9 & 4.7 & 3.0 & 60 & 31 & 0.09 & 0.015 \\
\hline 10 & Bengalon $60 \mathrm{Cm}$ & 4,5 & 0,81 & & 14 & 21 & 26 & 26 & 13 & 33 & \begin{tabular}{|l|}
4.82 \\
\end{tabular} & 0.14 & 0.13 & 17.12 & 45 & & 4.4 & 2.5 & 49 & 34 & 0.42 & 0.003 \\
\hline 11 & Bengalon (hutan) $20 \mathrm{C}$ & 4,2 & 0,93 & & 11 & 19 & 18 & 12 & 7 & & 3.95 & 0.09 & 0.10 & 13.4 & 58 & 21 & 3.8 & 2.0 & \begin{tabular}{|l|}
38 \\
\end{tabular} & 43 & 0.04 & 0.029 \\
\hline 11 & Bengalon (hutan) $60 \mathrm{Cm}$ & 4,2 & 0,82 & 0,06 & 13 & 19 & 16 & 9 & 4 & 0.26 & \begin{tabular}{|l|}
3.41 \\
\end{tabular} & 0.08 & 0.14 & 11.60 & 48 & 11 & 4.7 & 2.5 & 34 & 54 & $\begin{array}{ll}0.35 \\
\end{array}$ & 0.005 \\
\hline
\end{tabular}

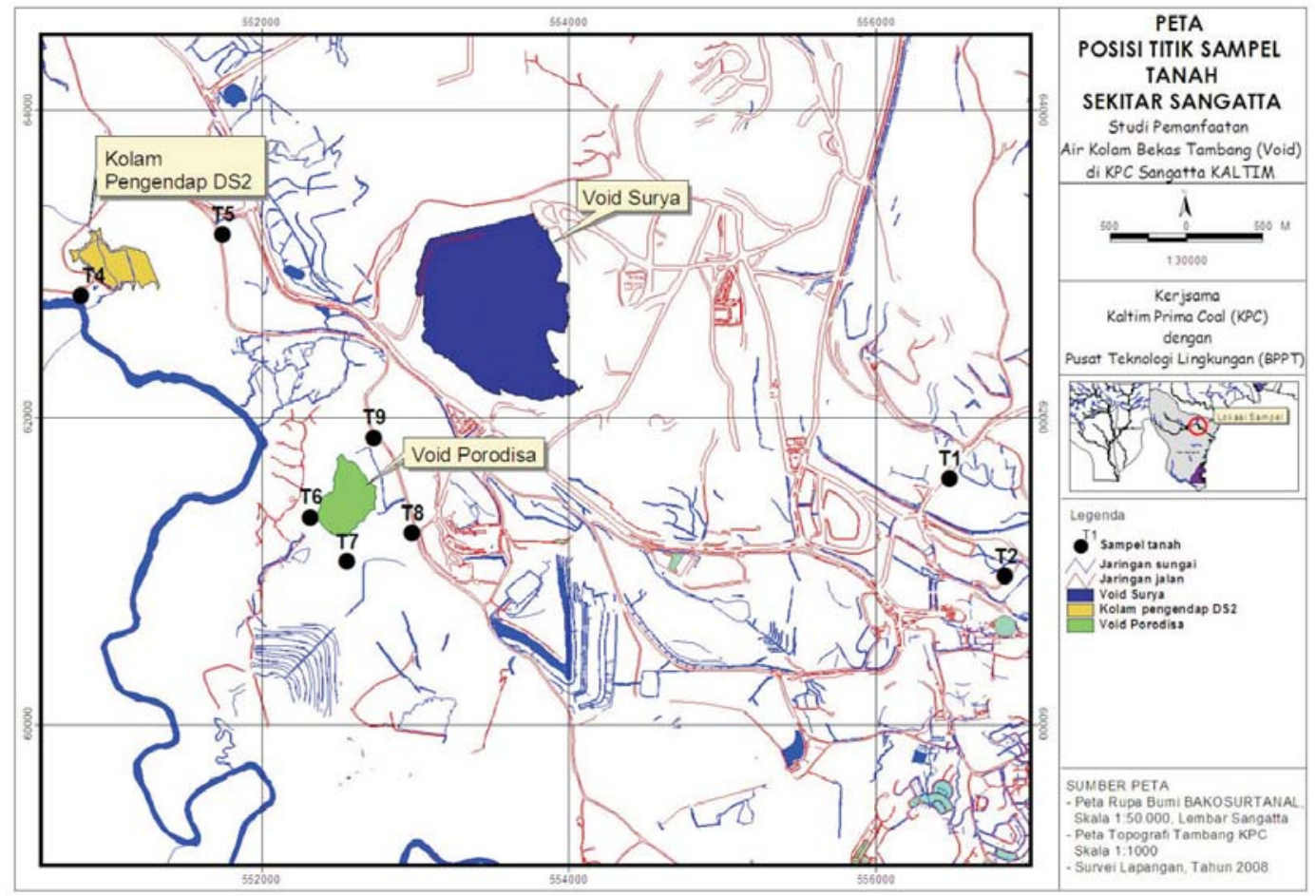

Gambar: Peta lokasi pengambilan sample tanah di Kabupaten Sangatta, Kal-Tim 